
$107 / 1 \cdot v$

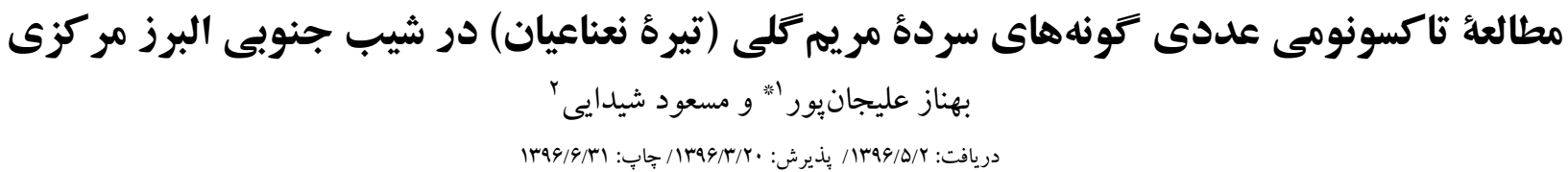

$$
\begin{aligned}
& \text { 'خروه زيستشناسى، دانشكدة علوم، دانشكاه اروميه، اروميه، ايران } \\
& \text { rادانشكدة علومزيستى، دانشكاه شهيد بهشتى، تهر ان، ايران }
\end{aligned}
$$

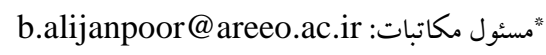

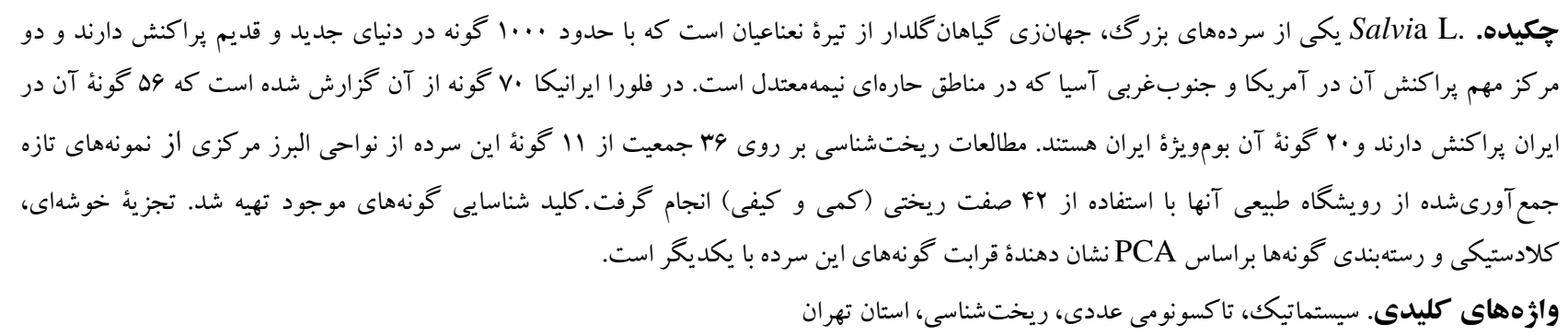

\title{
Numerical taxonomy study of Salvia L. (Lamiaceae) species in southern slope of Central Alborz, Iran
}

Behnaz Alijanpour ${ }^{1}$ \& Masoud Sheidai ${ }^{2}$

Received 24.07.2017/ Accepted 10.06.2017/ Published 22.09.2017

${ }^{1}$ Department of Biology, Faculty of Science, Urmia University, Urmia, Iran

${ }^{2}$ Faculty of Biology, Shahid Beheshti University, Tehran, Iran

${ }^{*}$ Correspondent author: b.alijanpoor@areeo.ac.ir

Abstract. The cosmopolitan genus salvia L. (Lamiaceae) consists of nearly 1000 species distributed throughout the Old and New Worlds. America and South West of Asia are the two most important distribution centers. Of the 70 species reported in the flora Iranica area nearly 56 species belong to Iran. This investigation deals with the morphology of Salvia. The morphological studies were performed on 36 populations of 11 species which grow in Central Alborz Mountains. In this analysis 42 quality and quantity characters were used. The results of this analysis have been used for the preparation of the identification key. Clustering, cladistics and PCA ordination reveals the relationships of the species in this genus.

Keywords. sysematic, morphometry, morphology, Tehran Province 
Nikian

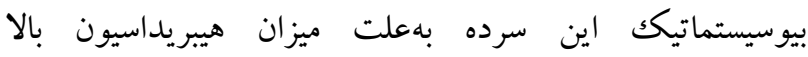
ضرورى است. با (Nakioglo, 2002; Pobedimova, 1954) توجه به : يراكنش برخى گو نههاى اين سرده در شيب جنوبى البرز

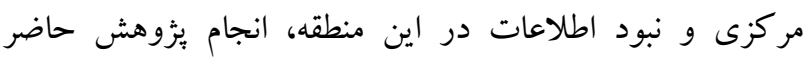

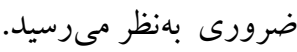

\section{مواد و روشها - ماد} مطالعات ريخت شناسى كونه ها و جمعيت هاى مورد بررسى

در اين مطالعه بررسىهاى ريختشناسى بروى تعداد 4\$ جمعيت

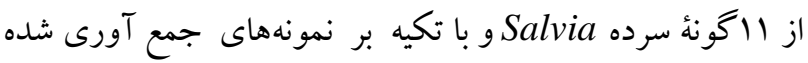

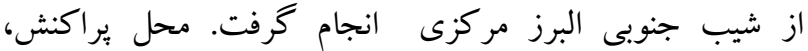
مختصات جغرافيايى و كد هرباريومى نمونها در جدول الرائه شده است. منطقة البرز جنوبى با وسعتى معادل 1991 ا هكتار در

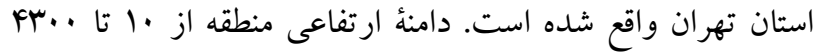

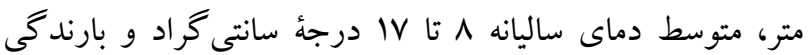
ساليانه آن .ذه تا ..11 ميلىمتر است. در اين منطقه ..11ا گونهُ

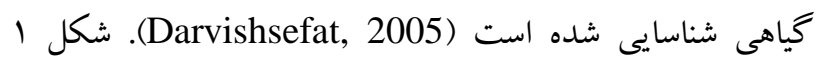
نقشه براكنش گونهها و جمعيتهاى Salvia در شيب جنوبى البر البرز

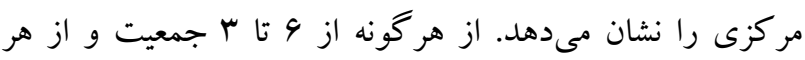

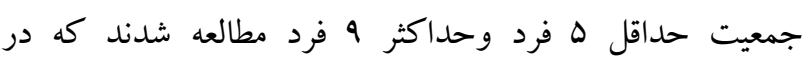

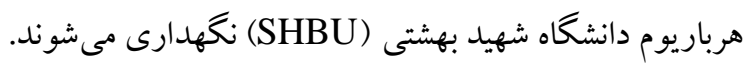
آناليز عددى صفات ريخت شناسى صفات كمى و كيفى مورد نياز براى انجام مطالعات ريخت - صداسئ

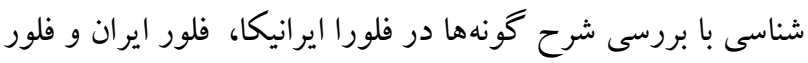

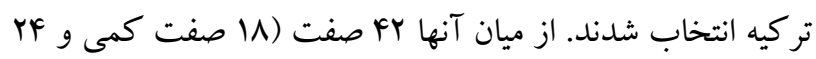
صفت كيفى) مورد تجزيه و تحليل آمارى قرار گرفتند (جدول با و

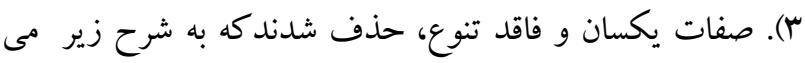
باشند: - n

فرم رويشى، اقسام برگك (از نظر رگبر گی)، غلاف لب بإينى

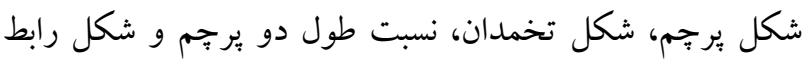

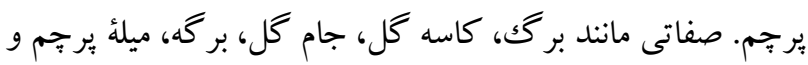

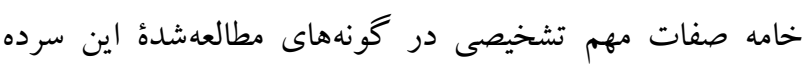

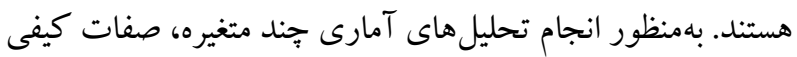

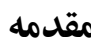

تيرهُ نعناعيان (Labiatae Juss.) (Rechinger, 1982) Lamiales Bromheaed بزركت ترين تيره از راسته

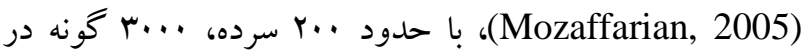
سراسر دنياى قديم و جديد براكنش دارند. اين گياهان داراى Shishkin, 1954; ) اهميت اقتصادى و دارويى هستند (Nakiöglu, 2002 (ز مهمترين سردههاى اين تيره مىتوان Thymus L. ، Lavandula L. Salvia L.،Mentha L. به Stachys L. ،Laminum L. ،

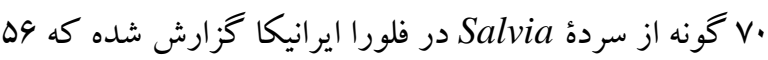

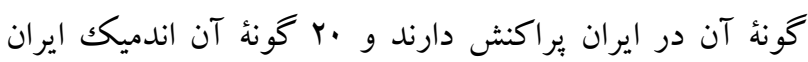
هستند (Rechinger, 1982). اين سرده همجنين داراى . ..د كونه در مركز و جنوب آمريكا؛ • ما كونه در آسياى مركزى، مديترانه و (Walker et al., 2004 و كونه در شرق آسيا است Nezahatk \& Emir, 2003 مديترانه، آسياى مركزى، مناطق مرتفع مكزيكك و جنوب كوههاى آند آمريكا مى باشد (Boissier, 1875). يكى از بزركترين سردههاى تيرهُ نعناعيان و شامل بيش

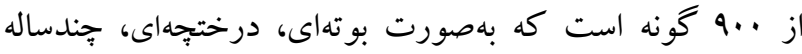
هستند. بسيارى از گونههاى اين سرده در پار ككها و باغها بهعنوان علف هرز نيز رويش دارند (Özdemir \& Gülcan, 1999). اين

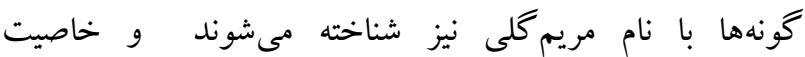
آنتىباكترى، آنتى اكسيدان و آنتىديابت دارند Özdemir \& Senel, 1999; Özkan \& Soy, 2007) سرده براى درمان بيمارى جشم و كنترل حافظه نيز به كار مىروند (Nezahatk \& Emir, 2003). مطالعات مورفومترى، ريز ريختشناسى و تشريحى متعددى روى اين سرده در ايران صورت كرفته است؛ از جمله Salvia (2012) Jamzad كونهُ سرده را از نظر تاكسونومى بررسى كرد. Kharazian (2012) با بال بررسى مورفومترى rا گونه از اين سرده تنوع مورفولوزيكى بالايى در برخى از گونهها مشاهده نمود. در شمالشرق ايران،

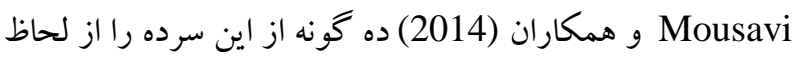
صفات ريز ريختشناسى و تشريحى مطالعه كردند. در شمال غرب ايران Habibvash و همكاران (2007) سا گونه را تحت بررسى قرار دادند و در مركز ايران نيز \& كونه توسط Jafari و 


$$
\text { جدول 1- گونها و جمعيتهاى تحت مطالعه و محل جمع آورى آنها. }
$$

Table 1. The studied species and populations and their localities.

\begin{tabular}{|c|c|c|c|c|}
\hline Rows & Taxon & $\begin{array}{l}\text { Voucher } \\
\text { No. }\end{array}$ & Locality & Collecctor \\
\hline 1 & S. nemorosa L. & 8500980 & Tehran, Haraz Road, Polur,Lar Rod, Ele: 2163m, N 35^ 51' 19", E 052^ 03’ 22.5" & B. Alijanpoor \\
\hline 2 & S. nemorosa L. & 8500981 & $\begin{array}{l}\text { Tehran, Chalous Road , between GHachsar and Nesa , Eel: 2150,N 36^ 05' 29.0", E 51^ } \\
\text { 18' 51.4" }\end{array}$ & B. Alijanpoor \\
\hline \multirow[t]{2}{*}{3} & S. nemorosa L. & 8500982 & Tehran, Haraz Road, Abali, Ele:1986m, N 35^ 45' 23.3", E 051^ 57’ 40" & B. Alijanpoor \\
\hline & S. nemorosa L. & 8500983 & $\begin{array}{l}\text { Tehran, Chalous Road, between Asara and Mahan, Eel: 1866m, N 36^ 01' 49.9".1"E 51^ } \\
13^{\prime} 22.5\end{array}$ & B. Alijanpoor \\
\hline 4 & S. nemorosa L. & 8500984 & Tehran, Parchin Road, KHojir, Ele: 1270m,N 35^ 93' 56.9", E 051^ 43’ & B. Alijanpoor \\
\hline 5 & S. nemorosa L. & 8500985 & Tehran, Chalous Road, Meydanak, Eel: 2126mm, N 36^ 06' 10.9" E 51^ 18' 54.1" & B. Alijanpoor \\
\hline 6 & S. hypoleuca Benth. & 8500986 & Tehran, Parchin Road, KHojir, Ele: 1300m, N 35^ 39' 7.1", E 051^ 43’ 1.9" & B. Alijanpoor \\
\hline 7 & S. hypoleuca Benth. & 8500987 & Tehran, Haraz Road, Polur, Lar Rod, Ele: 2163m, N 35^ 51' 19", E 053^ 03' 22.5" & B. Alijanpoor \\
\hline 8 & S. hypoleuca Benth. & 8500988 & Tehran, Tochall Mount, Ele:1857m, N 35^ 49' 14.1", E 051^ 24' 02.1" & B. Alijanpoor \\
\hline 9 & S. ceratophylla L. & 8500989 & Tehran, Firuzkoh Road, 10Km to Damavand, Ele:1842m, N 35^ 43' 53.2", E 51^ 55’ 34.1’ & B. Alijanpoor \\
\hline 10 & S. ceratophylla L. & 8500990 & Tehran, Abali Road, Sorkhehesar, Ele:1636m, N 35^ 43' 51.7", E 051^ 33’ 46.3" & B. Alijanpoor \\
\hline 11 & S. ceratophylla L. & 8500991 & Tehran, Chalous Road, Hesar, Ele: 1394m, N 35^ 49' 24.3", E 51^ 01'53" & B. Alijanpoor \\
\hline 12 & S. limbata C.A.Mey. & 8500992 & Tehran, Parchin Road, KHojir, Ele:1350m, N 35^ 39' 8", E 051^ 43’ 21" & B. Alijanpoor \\
\hline 13 & S. limbata C.A.Mey. & 8500993 & Tehran, Tochall Mount, Ele: 1850m, N 35^ 48,58.8", E 051^24' 05.4" & B. Alijanpoor \\
\hline 14 & S. limbata C.A.Mey. & 8500994 & Tehran, Firuzkoh Road, 10Km to Damavand, Ele: $1855 \mathrm{~m}, \mathrm{~N} 35^{\wedge} 43^{\prime} 0 "$ ",E 51^ 55' 51.2" & B. Alijanpoor \\
\hline 15 & S. verticellata $\mathrm{L}$. & 8500995 & Tehran, Haraz Road, Polur, Lar Rod, Ele: 2163m, N 35^ 51' 19", E 052^ 03' 22.5" & B. Alijanpoor \\
\hline 16 & S. verticellata $\mathrm{L}$. & 8500996 & $\begin{array}{l}\text { Tehran, Chalous Road, Between Asara and Mahan, Eel: 1864m, N 36^ 01’ 57.1"E 51^ 13' } \\
\text { 18.4" }\end{array}$ & B. Alijanpoor \\
\hline 17 & S. verticellata $\mathrm{L}$. & 8500997 & $\begin{array}{l}\text { Tehran, Chalous Road, Between GHachsar and Nesa, Eel: 2150, N 36^ 05' 29.0", E 051^ } \\
\text { 18' 51.4" }\end{array}$ & B. Alijanpoor \\
\hline 18 & S. sclarea L. & 8500998 & Tehran, Haraz Road, Polur, Lar Rod, Ele: 2163m, N 35^ 51' 19", E 052^ 03' 22.5" & B. Alijanpoor \\
\hline 19 & S. sclarea L. & 8501008 & Tehran, Lar Road, Rine, Ele. 2410m N 36 52, E 4235 & B. Alijanpoor \\
\hline 20 & S. sclarea L. & 85010013 & Tehran, Lavason & B. Alijanpoor \\
\hline 21 & S. staminea Montbr.\& Aucher & 8500999 & Tehran, Haraz Road, Abali, Ele: 1995m, N 35^ 45’ 031", E 051^ 57’ 25.5" & B. Alijanpoor \\
\hline 22 & S. staminea Montbr.\& Aucher & 85010014 & Tehran, Lavason & B. Alijanpoor \\
\hline 23 & S. staminea Montbr.\& Aucher & 85010015 & Tehran, Lar Road, Rine, Ele. 2410m N 36 52, E 4235 & B. Alijanpoor \\
\hline 24 & S. reuterana Boiss. & 8501000 & Tehran, Parchin Road, KHojir, Ele: 1288m, N 35^ 40’ 06.9", E 051^ 43’ 01.1" & B. Alijanpoor \\
\hline 25 & S. reuterana Boiss. & 8501001 & Tehran, Chalous Road, Beylaghan, Ele: $1363 \mathrm{~m}, \mathrm{~N} 35^{\wedge} 50^{\prime} 10.1^{\prime \prime}, \mathrm{E} 51^{\wedge} 03^{\prime} 05^{\prime \prime}$ & B. Alijanpoor \\
\hline 26 & S. reuterana Boiss. & 8501002 & Tehran, Haraz Road,Abali, Sadatmahalle, Ele: 1936m, N 35^ 44' 46.7", E 51^57'19" & B. Alijanpoor \\
\hline 27 & S. spinosa L. & 8501003 & Tehran, Chalous Road, Hesar ,Ele: 1934m, N 35^ 49' 24.3", E 51^ 01'53" & B. Alijanpoor \\
\hline 28 & S. spinosa L. & 8501004 & Tehran, Parchin Road, KHojir, Ele:1233m, N 35^ 33' 12.1", E 051^ 45’ 05.7" & B. Alijanpoor \\
\hline 29 & S. spinosa L. & 8501009 & Tehran, Chalus Road, Shemshak, Ele: 3620m, N 3, E 51^ 30'01^ & B. Alijanpoor \\
\hline 30 & S. xanthocheila Boiss. & 8501005 & Tehran, Chalous Road, GHachsar, Ele: 2165m, N 36^ 7' 15.6" , E 05^ 19’ 19.8" & B. Alijanpoor \\
\hline 31 & S. xanthocheila Boiss. & 8501006 & Tehran, Polur, Lar Rod, Ele: 2163m, N 35^ 51' 19",E 052^ 03' 22.5" & B. Alijanpoor \\
\hline 32 & S. xanthocheila Boiss. & 85010010 & Tehran, Emamzade Hashem, Ele: 2720m, N 35^ 46' 44.6" E 52^ 02' 19.8" & B. Alijanpoor \\
\hline 33 & S. atropana Bunge & 8501007 & Tehran, Polur, Lar Rod, Ele: 2163m, N 35^ 51' 19", E 052^ 03' 22.5" & B. Alijanpoor \\
\hline 34 & S. atropana Bunge & 85010011 & Tehran, Firouzkoh Road, Gilavand, Ele: 2480m, N 35^ 51' 19",E 053^ 03' 22.5 & B. Alijanpoor \\
\hline 35 & S. atropana Bunge & 85010012 & .Tehran, Haraz road, Bomhen, '17" , E 051^ 87' 19", 741N 2256m 35^ Ele & B. Alijanpoor \\
\hline
\end{tabular}



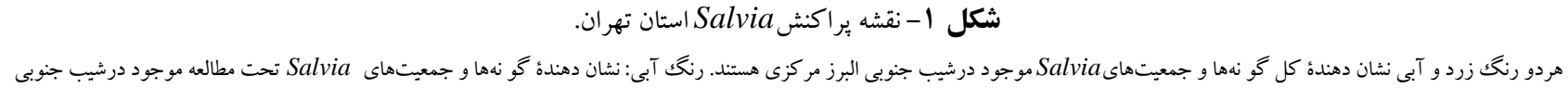

Fig. 1. Distribution map of Salvia, Tehran province

Both blue and yellow colors demonstrate all the species and populations of Salvia in southern slope of Central Alborz. The blue color represents the studied species and populations. 


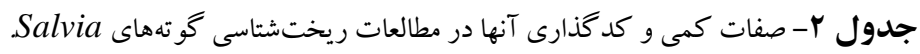

Table 2. Quantitative characters and their coding in morphological study of Salvia species.

\begin{tabular}{|c|c|}
\hline مقياس اندازه كيرى & رديف صفت \\
\hline 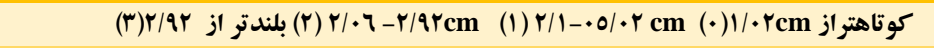 & 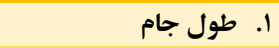 \\
\hline 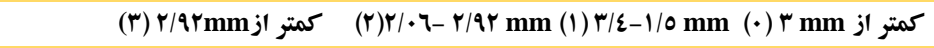 &  \\
\hline كمتر از & 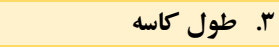 \\
\hline 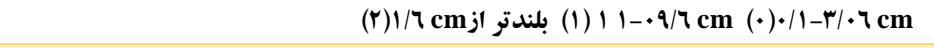 & ع. طول ميله يرجم \\
\hline 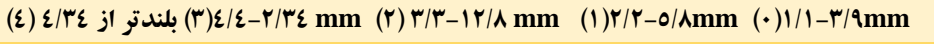 &  \\
\hline كو تاهتراز & 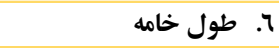 \\
\hline (r) $1 \cdot / 11-0 / \Lambda \mathrm{cm}(1) \mathrm{Y} / q_{-} \cdot \varepsilon / \mathrm{rcm}(\cdot) \varepsilon / \Upsilon-r \Lambda / / r \mathrm{~cm}$ & 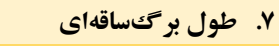 \\
\hline$(r) \wedge / q-1 / 9 \mathrm{~cm} \quad(1) \varepsilon / 0-r / A \mathrm{~cm} \quad(\cdot) \Gamma / \Gamma-0 \tau / \varepsilon \varepsilon \mathrm{cm}$ & 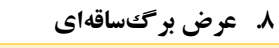 \\
\hline كوتاهتراز & 9. طول بركتقاعدهاى \\
\hline 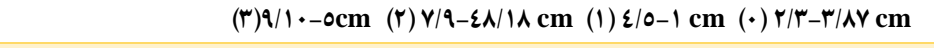 & • عرض بركى قاعدهاى \\
\hline$(r) \Gamma / r-r / 9 \mathbf{m m}(1) r / r-r / 0 \mathrm{~mm}(\cdot) 1 / \Gamma-\Lambda / 1 \mathrm{~mm}$ & 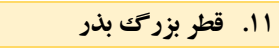 \\
\hline$(\boldsymbol{r}) 1 / \mathrm{r}-\mathrm{Y} \mathbf{m m}(1) 1 / 1-\varepsilon / \tau \mathbf{m m}(\cdot) 1-1 / \mathrm{r} \mathbf{~ m m}$ & 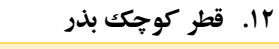 \\
\hline (广) $0-\varepsilon \mathbf{m m} \quad(\cdot) 1 / \mathrm{r}-0 / 0 \mathrm{~mm}$ & با. طول دمعل \\
\hline 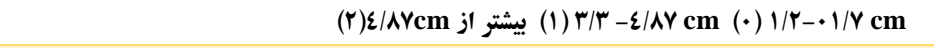 & ع ا. طول دمبر كَساقهاى \\
\hline 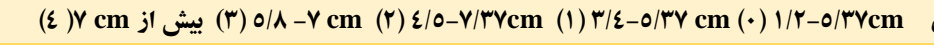 & 10. طول دمبر كتقاعدهاى \\
\hline  & 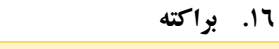 \\
\hline 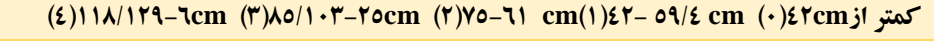 & 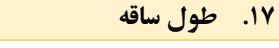 \\
\hline$(1)|7-1 \varepsilon(\cdot)| r-1 T$ & 11. تعداد ركبر كى كاسه \\
\hline
\end{tabular}

جدول r- صفات كيفى و كد گذارى آنها در مطالعات ريختشتاسى گوتههاى Salvia.

Table 3. Qualitative characters and their coding Salvia species.

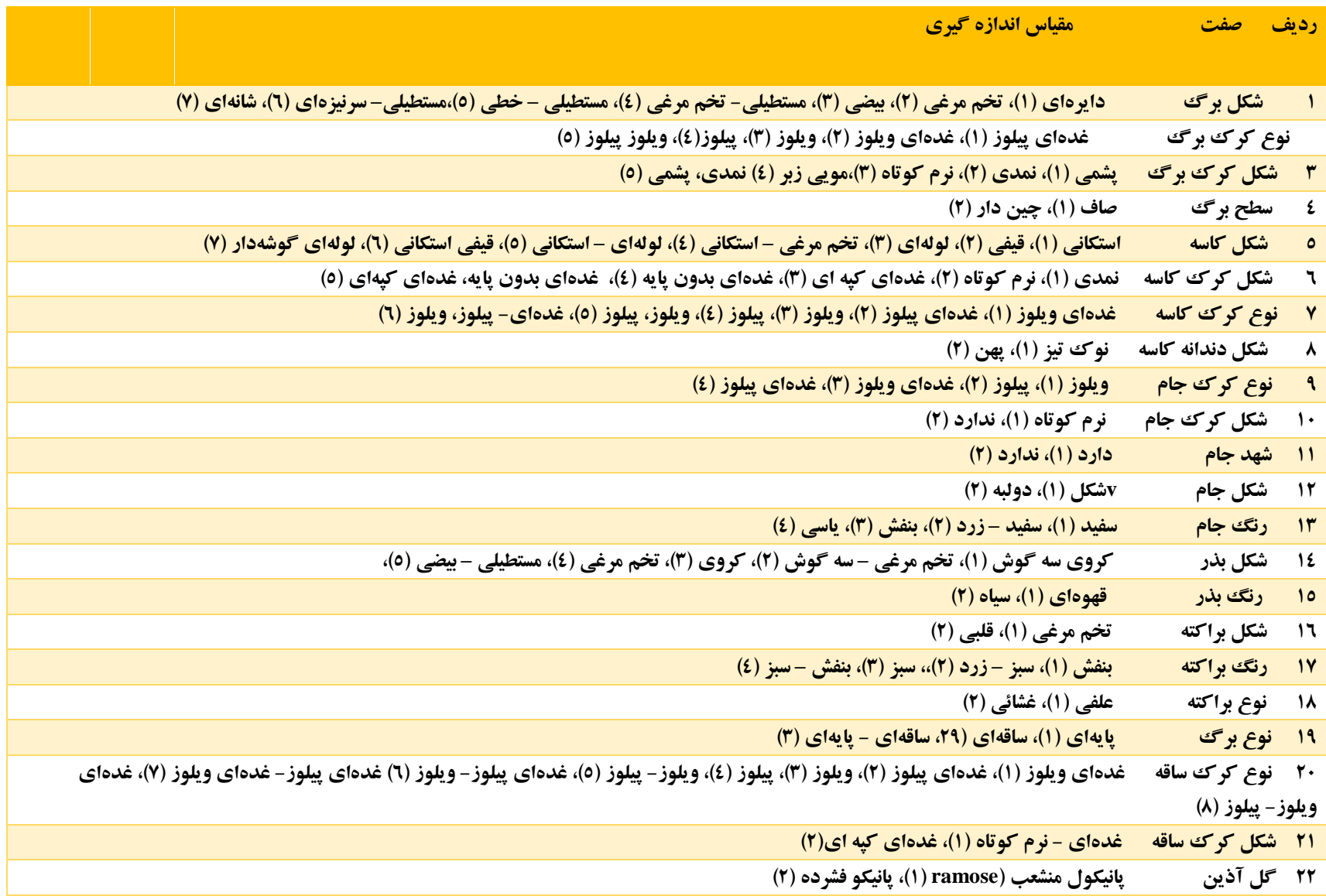


$\Delta$

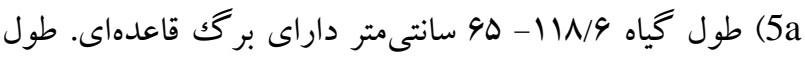
9 كاسه V-9 ميلى متر.

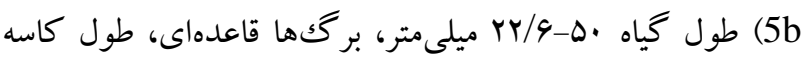
$\wedge$ 9-V/D 6a سطح ساقه فاقد كر كك يا داراى كر كك فلسمانند، طول براكته V م-ه/D 6b سطح ساقه داراى كر كك مركب يا ساده، طول براكته حدود S. sclarea L.

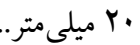

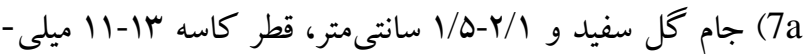

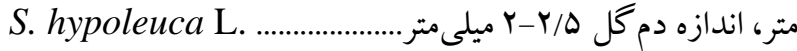

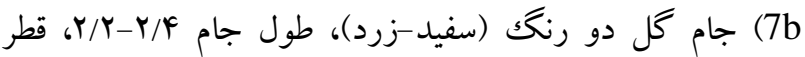
كاسه Q-1 ميلى متر اندازه دم گل ه-ه/ه ميلى متر...

S. limbata C.A.Mey.

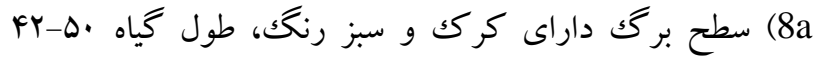

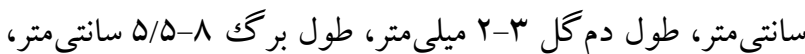
9

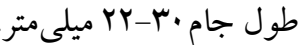
8b بركَ داراى كر كك خيلى زياد، مخملى و نقره اي رنگك، طول كياه צY-r S. xanthocheila Boiss. ... سانتىمتر، طول جام .ب-ها ميلى مترك 9a براكته علفى، نوكى براكته و كاسه داراى خار، سطح ساقه

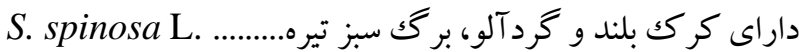
(9b براكته غشايى، نوكى براكته و كاسه بدون خار، برگك سبز،

S. reuterana Boiss. كرد آلو نيست

دندرو گرامهاى حاصل از روشهاى UPGMA و و و يارسيمونى (شكلهاى reighbor Joining) يلات رستهبندى PCA نتايج مشابهى را نشان دادند و جمعيتهاى UP- متعلق به هر كونه در كنار هم دستهبندى شدند. درختجه داراى دو شاخه اصلى است. در يكى از خوشهها (خوشأ اول) جمعيت هاى گونهُ S. hypoleuca و در خوشهُ ديكر كه خود به دو خوشهُ اصلى تقسيم مى شود بدين صورت است كه در خوشهُ اول آن گونهاى S.nemorosa و verticellata قرار دارند كه با نزديكى گونهها در فلورا ايرانيكا مطابقت دارد و در خوشهُ دوم شامل زير خوشههاى متعددى است كه در اولين زير خوشة آن گونهاى S.limbata و S.ceratophylla نزديك هم
بهصورت دوحالته و جندحالته كدگذارى شدند و براى صفات كمى از ميانگين اندازه گيرىها در افراد و جمعيتها استفاده شد. براى تعيين قرابت گونهها و جمعيتهاى تحت مطالعه از نرمافزار NYSYS و PAUP استفاده شد. گ ₹روه بندى نمونهها با استفاده از روشهاى تجزئ خوشهاى مانند UPGMA،

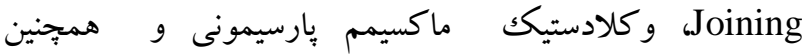
رستهبندى گونها بر اساس آناليز تجزيه مؤلفههاى اصلى (PCA) انجام كرفت. Boot strap خوشه شاى بدست آمده T تعيين شد. در روش تجزيه به مؤلفهاى اصلى (PCA) مقادير ويثٔه دو مؤلفه اصلى حدود · V تعيين شدند.

بحث و نتايج كليد شناسايى كونههاى مطالعه شده سرده Salvia (شيب جنوبى البرز مركزى)

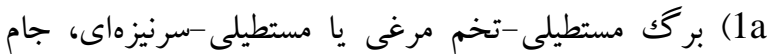

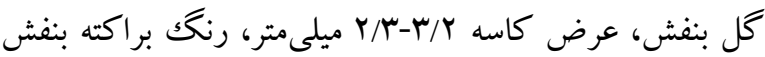
سبز يا سبز-زرد، لوله جام بدون كركك فلس مانند و داراى

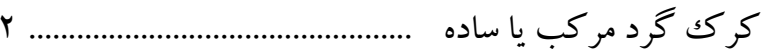
1b برگك شانهاى يا بيضى يا تخممرغى يا دايرهاى، جام كل سفيد

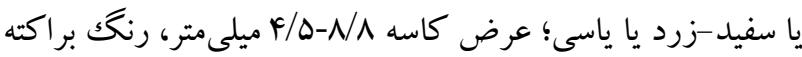
سبز، لوله جام داراى كركك فلس مانند و يا بدون كركك و صاف r

(2a

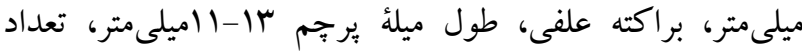
ركبر گك كاسه r ا، رنگك بذر سياه، شكل بذر تخم مرغى.

S. nemorosa L.

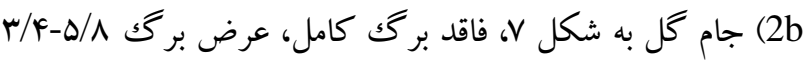

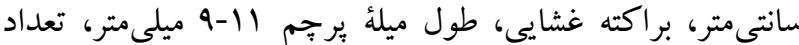
ركبر گك كاسه F ا، رنگك بذر قهوهاى، شكل بذر بيضى - مستطيل

S. verticellata $\mathrm{L}$.

(3a برگك شانهاى و با حاشيه مستطيلى - خطى

S. ceratophylla L.

f (3b بر گها كامل با حاشيه دندانهاى درشت

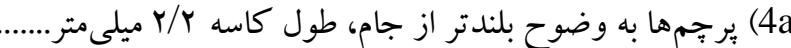
S. staminea Montbr. \& Aucher (4b برجمها به وضوح بلندتر از جام نيستند، طول كاسه 19-1 
حاضر به هم قرابت دارند، طبق مطالعات Vaezi و همكاران (2005) از لحاظ مطالعات آناتوميكى دمگل و دمبرگك نيز كنار

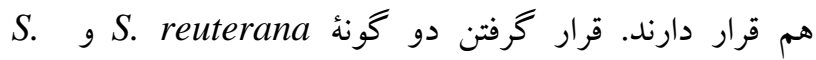
atropatana و از نظر مولكولى نيز با خوشهبندى (1982a) Hedge مطالعات Sajadi و همكاران (2009) مطابقت دارد. در كلادو كرام NI افزايش طول دمبرگك و براكته وشكل كاسه بيشترين تأثير رادر جدايى گونها و جمعيت ها دارند و وجود و


جمعيتها داشتند. در كلادوگرام تجزيه به مولفهاى اصلى افزايش طول دمبرگ، تعداد رگبر گك كاسه، شكل كاسه و شكل دانه كرده بيشترين تأثير رادر جدايى كونهها و جمعيتها دارند و وجود و شكل جام و نوع گل آذين كمترين تأثير را در

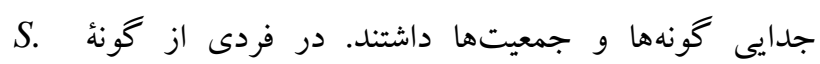
xanthocheila كه با بقيه افر اد اين گونه كه عمدتاً ميله برجّم به طوله تا ال 11 ميلى متر دارند متفاوت است كه اين تفاوت مى تواند ناشى از وارياسيون

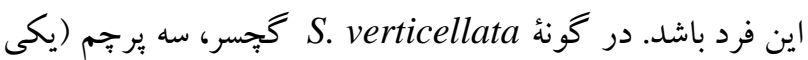
كو جُك و دوتا بزركَ) مشاهده شدند. جنسى جديد و در حال گونهزايى است. با بررسى S. verticellta كاريوتايب و رفتار ميوزى روى اين سرده، گُنه در جادهُ جالوس توسط (Sheidai \& Alijanpoor, 2011) براى اولين بار تترايلوييد گزارش شده است كه تا حدودى گونهزايى را در اين جنس تأييد مى كند. با مقايسٔ نتايج كونهاى جنس Salvia مطالعهشده با منابع معتبر مذكور، جمعيتهاى گونه بهخوبى از هم تفكيك شدند. گُونهاى نزديك به بهم اين جنس، عمدتا در گروهايى در كنار هم قرار مى گيرند كه با فلورا ايرانيكا مطابقت دارد، ولى استثناهايى هم مشاهده مىشود. بعضى صفات مورفومترى مثل طول برجم بهخوبى بين گونها تمايز ايجاد نكردند و تا حدى بين آنها در هم آميختخى ايجاد كردند. وجود هيبريداسيون بين جمعيتهاى گونهاى باعث تنوع مورفولوزى در اين جنس است (Hedge, 1982a). رفتارهاى ناهنجار ميوزى مثل

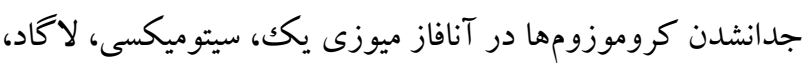
جسبندگى و غيره مى توانند سبب تنوع درون گونهاى اين سرده هستند (Sheidai et al., 2010). تنوع فنوتيبى در كونه هاى سرده
قرار دارند كه با نزديكى گونهها در فلورا ايرانيكا مطابقت ندارد. در خوشة ديخر كونهاى S. Staminea و نزديك هم قرار دارند كه با نزديكى گونهها در فلورا ايرانيكا مطابقت ندارد و كونهاى S.reuterana و S. spinesa نزديك هم قرار دارند. در دندرو گرام UPGMA افزايش مقادير طول جام و برجم و قطر كاسٔ گل بيشترين تأثير را در جدايى

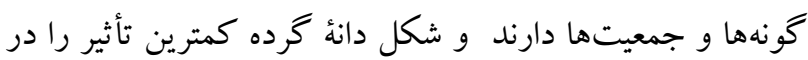
S. جدايى كونها و جمعيتها داشتند. در كلادو كرام يارسيمونى nemorosa بهعنوان برون گروه محسوب مىشود. در اين درختجه گونههاى

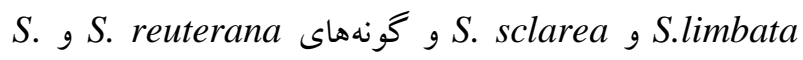
spinosa S. xanthocheil قرابت دارند كه با فلورا ايرانيكا مطابقت ندارد. جمعيتهاى كونهُ S. hypoleuca است و جمعيتهاى خجير و توجال موجود در يكك شاخه، با هم قرابت دارند و جمعيت يلور، بهعلت بزرگكتر بودن صفات كمى قطر كاسه، طول و عرض بذر و طول براكته با آنها قرابت دارند. جمعيتهاى گونهُ S. ceratophylla با بوت استرب 99٪ بهوضوح از بقيه گونهها و جمعيتها متمايز مىشوند كه جمعيت دماوند و سرخه حصار تشكيل يكك خوشه را مىدهند و جمعيت سرخه حصار بعلت كمتر بودن طول كاسه، طول ميله برجم و بزركتر بودن اندازه قطر بذر، نزديك آن دو جمعيت قرار دارد. همجنين همانطوريكه در شكل ب مشاهده مىشود، وضعيت مشابهى از لحاظ جدايى جمعيتها و بوت استرب بالا در جمعيتهاى هر يكك از كونه هاى S. S. reuterana S. limbata S. stamine $S$. atro-paana s. xanthocheilla spinosa نيز وجود دارد. جمعيت هاى گونهاى S. verticellata با بوت استرب 9V٪ از ديخر گونه هاى و جمعيت جدا شده است كه دو جمعيت جاده جالوس كنار هم و جمعيت بلور بعلت بزرگتر بودن كليه صفات كمى در نزديك آن قرار دارد. عدم تطابق قرابت S. Sونهاى S. ceratophylla با هم و كو S. S. limbata و stamina ايرانيكا، به بررسىهاى مطالعات مولكولى، ميكرومورفولوزى نياز

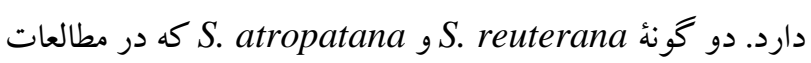




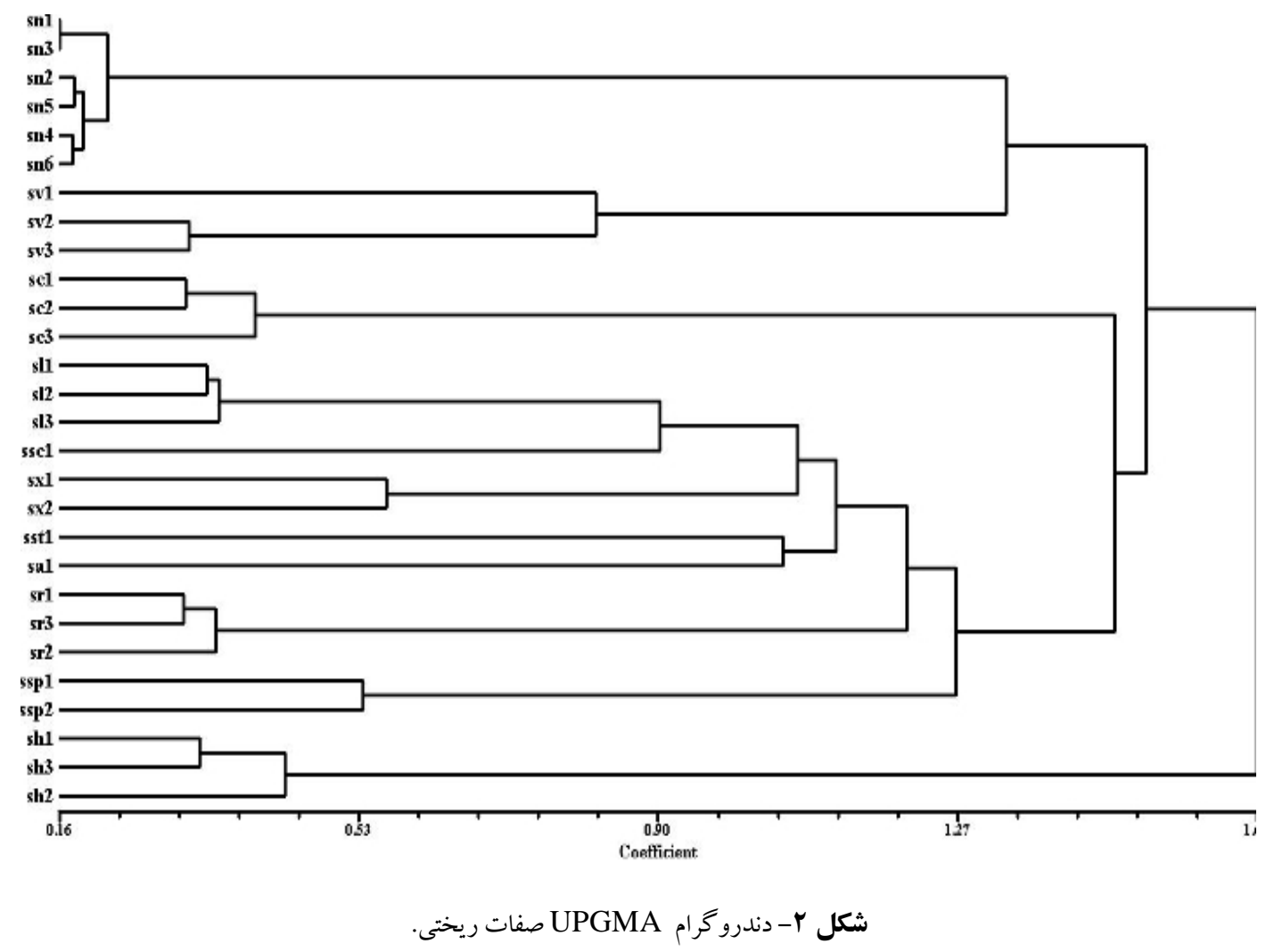

Fig. 2. UPGMA dendrogram of morphological characters.

$\mathrm{Sn}=$ S.nemorosa, $\mathrm{Sv}=\mathrm{S}$. verticellata, $\mathrm{Sc}=\mathrm{S}$. ceratophylla, $\mathrm{Sl}=\mathrm{S}$. limbata, $\mathrm{Ssc}=\mathrm{S}$. sclarea, $\mathrm{Sx}=\mathrm{S}$. xanthocheilla, $\mathrm{Sst}=\mathrm{S}$. stamine, $\mathrm{Sa}=\mathrm{S}$. atropaana, $\mathrm{Sr}=\mathrm{S}$. reuterana, $\mathrm{Ssp}=\mathrm{S}$. spinosa, $\mathrm{Sh}=\mathrm{S}$. hypoleca.

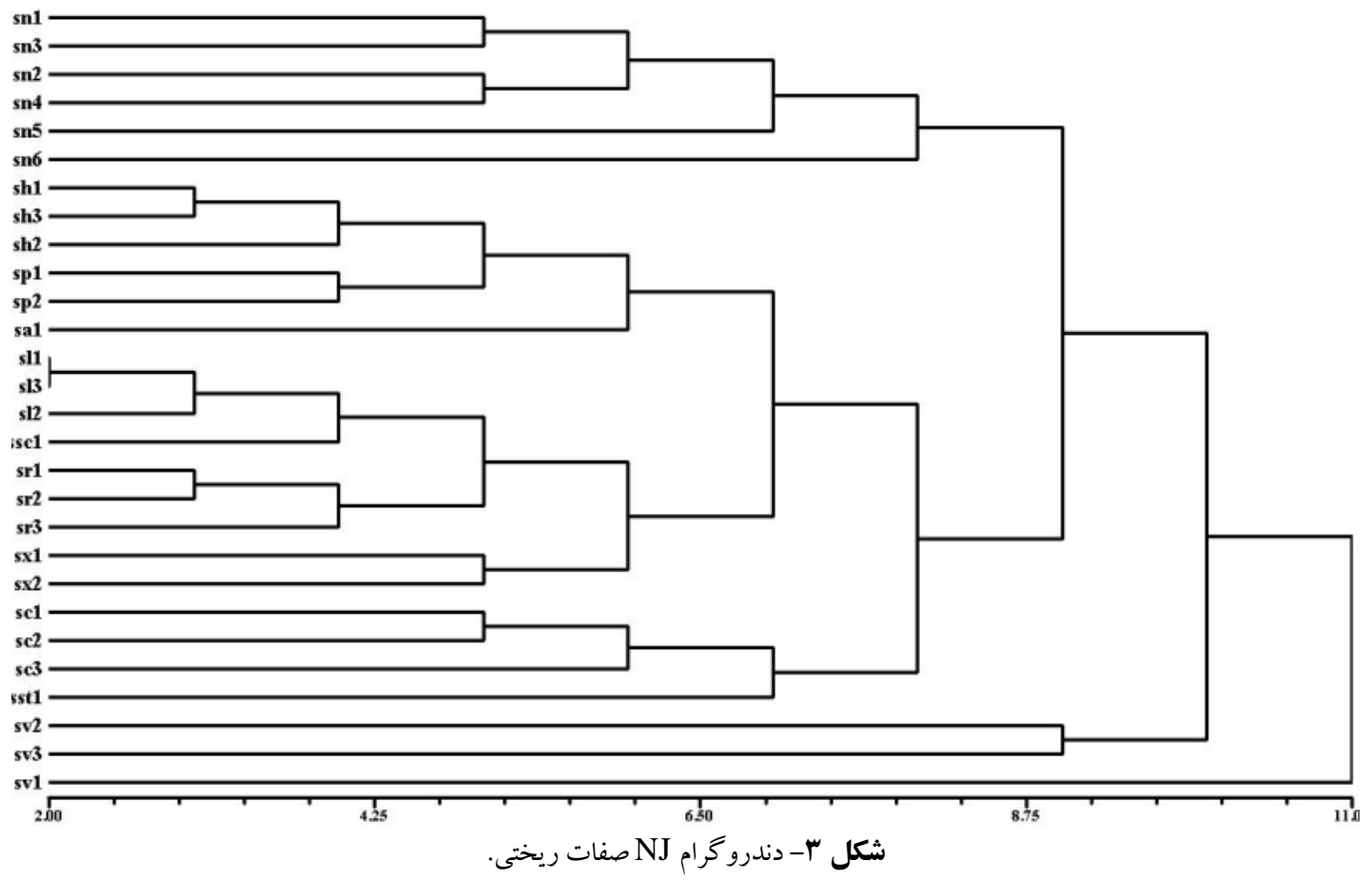

Fig. 3. NJ dendrogram of morphological characters.

$\mathrm{Sn}=$ S.nemorosa, $\mathrm{Sv}=\mathrm{S}$. verticellata, $\mathrm{Sc}=\mathrm{S}$. ceratophylla, $\mathrm{Sl}=\mathrm{S}$. limbata, $\mathrm{Ssc}=\mathrm{S}$. sclarea, $\mathrm{Sx}=\mathrm{S}$. xanthocheilla, $\mathrm{Sst}=\mathrm{S}$. stamine, $\mathrm{Sa}=\mathrm{S}$. atropaana, $\mathrm{Sr}=\mathrm{S}$. reuterana, $\mathrm{Ssp}=\mathrm{S}$. spinosa, $\mathrm{Sh}=\mathrm{S}$. hypoleca . 


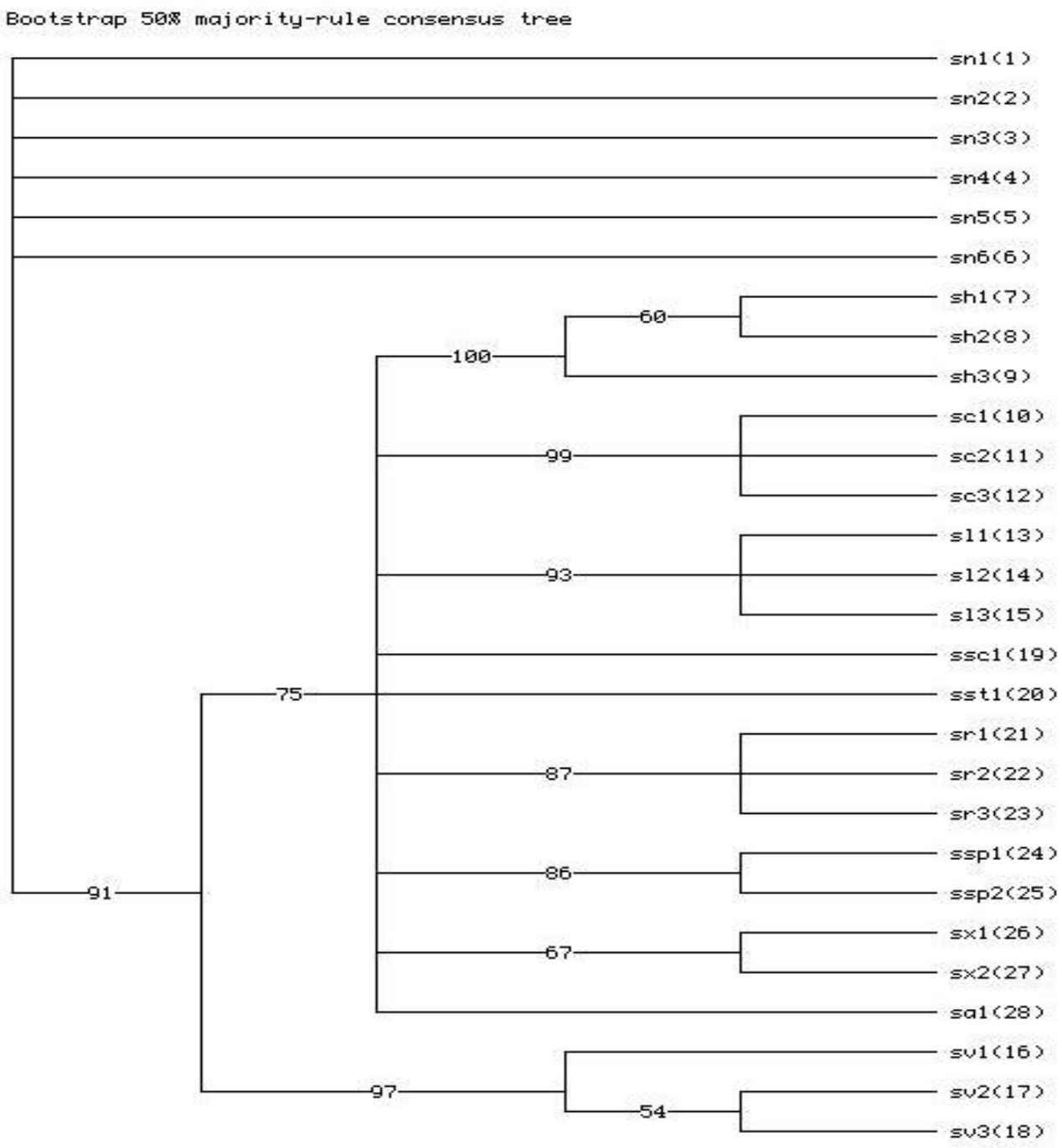

شكل ع- كلادو گرام بارسيمونى صفات ريختى.

Fig. 4. Parsimony dendrogram of morphological characters.

$\mathrm{Sn}=\mathrm{S}$. nemorosa, $\mathrm{Sv}=\mathrm{S}$. verticellata, $\mathrm{Sc}=$ S. ceratophylla, $\mathrm{Sl}=\mathrm{S}$. limbata, $\mathrm{Ssc}=$ S. sclarea, $\mathrm{Sx}=$ S. $x$ anthocheilla, $\mathrm{Sst}=\mathrm{S}$. stamine, $\mathrm{Sa}=\mathrm{S}$. atropaana, $\mathrm{Sr}=\mathrm{S}$. reuterana, $\mathrm{Ssp}=\mathrm{S}$. spinosa, $\mathrm{Sh}=\mathrm{S}$. hypoleca .

\section{REFERENCES}

Aktas, K., Ozdemir, C., Ozkan, M., Akyol, Y. and Baran, P. 2009. Morphological and anatomical characteristics of Salvia tchihatcheffii endemic to Turkey. - Afr. J. Biotech. 8: 4519-452.

Baran, P. and Özdemir, C. 2008. The Morphological, anatomical and karyological properties of Salvia napifolia Jacq. In: Terkey. - Bangladesh J. Bot. 35: 7784.

Boissier, E. 1975. Flora orintalis. Vol. 4. Asher and co. B.V., Amsterdam, ISBN: 906123 2031, PP: 590-636.

Darvishsefat, A.A. 2005. Atlas of protected areas Iran. University of Tehran Press. pp 68-70.

Habibvash, F., Rajamand, M.A., Sarghein, S.H., Heidari, R. and Ricani, M.H. 2007. Anatomical obse-

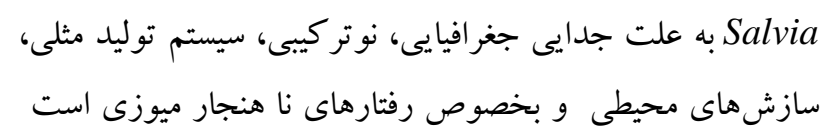

(Aktas et al., 2009; Baran et al., 2008; Haque, .(1983; Wang et al., 2007

$$
\begin{aligned}
& \text { از زحمات خانم هجرانه عزيزى كه از نقطه نظرات ايشان در اين } \\
& \text { مقاله استفاده شده است، كمال تشكر را داريم. }
\end{aligned}
$$


rvations on nutlets of some Salvia species (Lamiaceae) from West Azarbaijan in Iran. - Pak. J. Biol. Sci.10: 3385-3389.

Habibvash, F. 2007. Studied chemitaxonomy and anatomy several species of Salvia. - Master Thesis, Urmia University.

Haque, M.S. 1983. Phenotypic variability in foliar characters of some Salvia species. - Proc. Indian Nat. Sci. Acad. 49: 447-451.

Hedge, I.C. (1982a). Labiateae. In: P. H. Davis (Ed), Flora of Turkey and the Eastern Aegaean Islanda. Edinburgh, 7, 36- 463.

Hedge, I.C. (1982b). Salvia L. - In: Rechinger, K.H. (ed.): Flora Iranica 150: 403-476. - Akad. Druck- und Verlagsanstalt, Graz.

Jafari, A. and Nikian, M. 2008. Micromorphological, anatomical and pollen ornamentation study on four desert species of Salvia in Center of Iran. - Asian J. Plant Sci. 7: 736-741.

Jamzad, Z. 2012. Flora Iran, N. 76: Lamiaceae. - Research Institute of Forests and Rangelands, Tehran. pp 1074.

Kharazian, N. 2012. Morphometric study of some Salvia L. (Lamiaceae) species in Iran. - Scientific Journal of Biological Sciences 1: 126-137.

Mousavi, M., Jafari, A. and Najafi, Sh. 2014. Anatomical and micromorphological studies on leaves of Salvia L. species in Iran. - J. Rom. Biotech. Lett. 19: 90589068.

Mozaffarian, V. 1995. The Classification of Plants, Morphology Taxonomy. - Amir Kabir Publishing House, Tehran, pp 501.

Mozaffarian, V. 1995. The Classification of Plants: Morphology Taxonomy. - Amir Kabir Publishing House, Tehran. pp 610.

Nakiöglu, M. 2002. The classification of the Salvia L. (Labiatae) species distribution in West Anatolia according to penolic compounds. - Turk. J. Bot. 26: 103-108.

Nezahat, K. and Emir, A. 2003. The morphological, anatomical and karyological properties of Salvia techihatcheffii Endemic to Terkey (Lamiaceae). - Afr. J. Biotechnol. 8: 4519-4528.

Özdemir, C. and SENEL, G. 1999. The morphological, anatomical and karyological properties of Salvia sClarea L. - Tr. J. of Bot. 23: 7-18.

Özkan, M. and Soy, E. 2007. Morphology, anatomy, hair and karyotype structure of Salvia blepharoclaena Hedge \& Hub.-Mor. (Lamiaceae), endemic to Turkey. - Pak. J. Biol. Sci. 10: 893-898.

Pobedimova, E.G. 1954 Salvia. - In: Schischkin, B.K. (ed.) Flora of the U.S.S.R. 21: 154-255. - Izdatel'stvo Akademii Nauk SSR, Moscow.

Sajadi, S., Shiran, B., Kharazian, N., Hoshmand, S. and Sorkhe, K. 2009. Study of genetic diversity of the species of Salvia Chahar Mahal and Bakhtiari, Isfahan using AFLP markers. - J. Hortic Sci. 40: 7988.

Sheidai, M. and Alijanpoor, B. 2011. Karyotype analysis some salvia species (Lamiaceae) of Iran. - Cytologia 76: 425-429.

Sheidai, M., Alijanpoor, B., and Khayyami, M. 2010. Contribution to cytology of genus Salvia L. (Lamiaceae) in Iran. - Karyology 63: 405-410.

Walker, J.B., Sytsma, K.J., Treutlein, J. and Wink, M. 2004. Salvia (Lamiaceae) is not monophyletic: implications for the systematic, radiation, and ecological specializations of Salvia and Tribe Mentheae. - Am. J. Bot. 91: 1115-1125.

Wang, Y.R., Hanson, J. and Mariam, Y.W. 2007. Effect of sulphuric acid pretreatment on breaking hard seed dormancy in diverse accessions of five wild Vigna species. - Seed. Sci. Technol. 35: 550-559.

How to cite this article:

Alijanpour, B. and Sheidai, M. 2017. Numerical taxonomy study of Salvia L. (Lamiaceae) species in southern slope of Central Alborz, Iran. - Nova Biologica Rep. 4: 107-115.

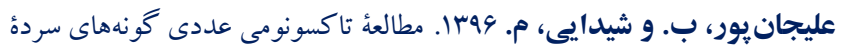

$$
\begin{aligned}
& \text { Salvia L. } \\
& \text { زيستى \&: }
\end{aligned}
$$

